\title{
Stage IVA Cervical Cancer AJCC v6 and v7
}

National Cancer Institute

\section{Source}

National Cancer Institute. Stage IVA Cervical Cancer AJCC v6 and v7. NCI Thesaurus.

Code C6323.

Stage IVA includes: T4, Any N, M0). T4: Tumor invades mucosa of bladder or rectum, and/or extends beyond true pelvis (bullous edema is not sufficient to classify a tumor as T4). M0: No distant metastasis. (AJCC 6th and 7th eds.) 